\title{
Bases do Pensamento Fenomenológico e Existencial em William James
}

Existential and Phenomenological Bases in William James

Bases del Pensamiento Fenomenológico y Existencial en William James
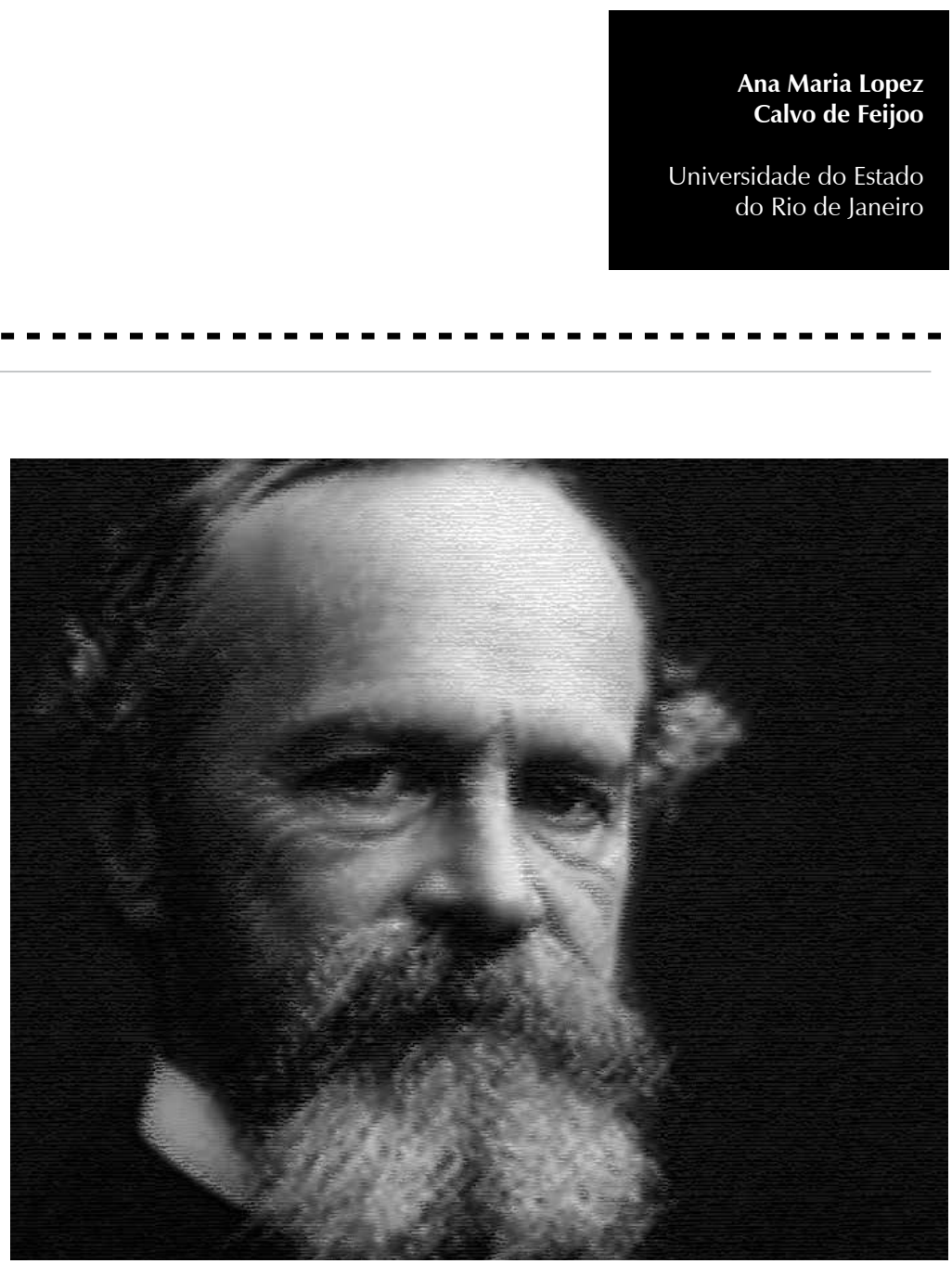
Resumo: Neste artigo, temos por objetivo investigar os fundamentos e as bases do pensamento fenomenológico e existencial advindos da Psicologia de William James no que diz respeito à noção de consciência, método e prática clínica. Para tanto, analisamos algumas obras de James e dividimos as suas propostas em três momentos distintos: pragmatismo, funcionalismo e empirismo. Por meio das elaborações em cada um desses momentos, tentamos esclarecer os pontos de encontro e os pontos de desencontro com os pensamentos fenomenológico e existencial. Concluímos que o ponto de encontro diz respeito à tentativa de não objetivação da consciência. Quanto ao desencontro, consideramos que James ainda toma a consciência como objeto da Psicologia e que a fenomenologia e as perspectivas existenciais se afastam da ideia de objeto, uma vez que não consideram a consciência contraposta ao mundo. Outro desencontro apresenta-se na acentuada divergência entre James e o pensamento fenomenológico e existencial no que se refere ao método e à prática bem como aos objetivos da clínica.

Palavras-chave: James (William). Fenomenologia existencial. Psicologia e Filosofia. Consciência.

Abstract: In this article, our goal is to investigate the foundation and the basis of existential and phenomenological thought of Psychology by William James, regarding the notion of consciousness, method and clinical practice. For both, we analyze some works of James and divide their proposals into three distinct periods: pragmatism, functionalism and empiricism. By means of the elaboration in each of these moments, we try to clarify the points of encounter and the points the confrontation with the existential and phenomenological thought. We conclude that the meeting point concerns the attempt of not objectification of consciousness. Regarding the mismatch, we believe that while James still takes consciousness as object of psychology and that phenomenology and existential perspectives deviate from the idea of object, since they do not consider the consciousness versus the world. Another mismatch is presented in the sharp disagreement between James and the existential and phenomenological thought regarding method and practice as well as the goals of the clinic.

Keywords: James (William). Existential phenomenology. Psychology y Philosophy. Consciousness.

Resumen: En este artículo, tenemos como objetivo investigar los fundamentos y las bases del pensamiento fenomenológico y existencial oriundos de la Psicología de William James en lo que respecta a la noción de conciencia, método y práctica clínica. Para eso, analizamos algunas obras de James y dividimos sus propuestas en tres momentos distintos: pragmatismo, funcionalismo y empirismo. Por medio de las elaboraciones en cada uno de esos momentos, intentamos aclarar los puntos de encuentro y los puntos de desencuentro con los pensamientos fenomenológico y existencial. Concluimos que el punto de encuentro trata sobre el intento de la no objetivación de la conciencia. En relación al desencuentro, consideramos que James aún toma la conciencia como objeto de la Psicología y que la fenomenologia y las perspectivas existenciales se alejan de la idea de objeto, ya que no consideran la conciencia contrapuesta al mundo. Otro desencuentro se presenta en la acentuada divergencia entre James y el pensamiento fenomenológico y existencial en lo que se refiere al método y a la práctica así como a los objetivos de la clínica.

Palabras clave: James (William). Fenomenologia existencial. Psicología y Filosofía. Conciencia.

O título Psicologia: Fundamentos e Bases do Pensamento Fenomenológico e Existencial diz respeito a uma disciplina do curso de graduação de Psicologia Clínica da Universidade do Estado do Rio de Janeiro, de cuja ementa constam conteúdos referentes ao pensamento de William James, Henry Bergson, Wilhem Dilthey, Franz Brentano, Sören Kierkegaard, Edmund Husserl, Martin Heidegger e Jean-Paul Sartre. Acreditamos que, ao compor esse ementário, o corpo docente original desse curso via nesses estudiosos a espinha dorsal que sustenta a temática principal da perspectiva fenomenológicoexistencial em Psicologia. Isso conduz hoje à seguinte questão: por que buscar em
James, Bergson e Dilthey fundamentos da perspectiva fenomenológica e existencial? Por que não retroceder, iniciando por Brentano, já que - como nos lembra Boris (2011) - é esse pensador o precursor inquestionável das perspectivas fenomenológicas, existenciais e humanistas em Psicologia? Para responder a essas questões, primeiramente, precisamos esclarecer algo mais fundamental: o que há em comum em todos esses estudiosos que é de especial interesse para a Psicologia com bases fenomenológicas e existenciais?

De forma resumida, pode-se dizer que todos esses estudiosos, a sua maneira, estudaram a consciência, mesmo que com diferentes 
posicionamentos e denominações e até mesmo defendendo a sua negatividade, colocando-se a favor ou contra ao modo como a consciência vinha até então sendo estudada e considerada. E alguns poucos, também, apostavam em outros métodos para conduzir seus estudos sobre o fenômeno da consciência. Todos, de um modo ou de outro, mais cedo ou mais tarde, tentam deslocar-se dos estudos epistemológicos sobre a consciência, que pressupõem a consciência (sujeito) apartada do mundo (objeto), e assim tentam resolver o problema do conhecimento, da verdade e de seu acesso. E é contra essa tese que todos esses autores se posicionaram.

A consciência, com as suas diferentes denominações (eu, sujeito e subjetividade, dentre outras), passa, graças a esses pensadores, por sérias revisões e formulações. Sem dúvida, na medida em que a concepção de eu sofre modificações, toda a Psicologia, tanto em suas teses como em suas práticas, inclusive a clínica, também se reformula.

Para esclarecer as questões aqui anunciadas, deter-nos-emos apenas nos possíveis legados de William James à Psicologia com bases fenomenológicas e existenciais. Essa tarefa, nada fácil, exige que nos debrucemos sobre algumas de suas obras para procurar seus fundamentos e desdobramentos afins com a fenomenologia e a filosofia da existência.

Alguns estudiosos desse tema posicionamse de formas totalmente divergentes ao tentarem organizar as temáticas jamesianas. Tripicchio (2007) identifica dois momentos distintos e até mesmo contraditórios em James: o filosófico e o psicológico. Já Gutman (2008) considera que a filosofia e a psicologia de James formam uma unidade. Ferreira e Arruda compartilham desse posicionamento ao afirmarem que o pragmatismo jamesiano está intimamente vinculado à Psicologia funcionalista. Os autores ressaltam que "é na filosofia de
James, e mais especificamente no seu pragmatismo, que a orientação funcionalista ganha força" (2010, p.77). Já Tourinho (2009), ao abordar os fundamentos epistemológicos da Psicologia, confirma a importância de James, referindo-se a ele como brilhante psicólogo da corrente da consciência e finaliza chamando a atenção para a polêmica provocada pelo autor, com as suas dúvidas acerca da existência da consciência. Parece, então, que Tourinho também identifica pelo menos outro momento em que o psicólogo funcionalista não mais reconhece a entidade consciência.

Como vimos James, em seus escritos, abre um espaço rico, intenso e disperso repertório de discussões. $\mathrm{E}$, embora não tenha sido o precursor de nenhuma escola em Psicologia, tais como foram Rogers e Freud, entre outros, ainda podemos constatar um ou outro estudioso dessa área de estudo situar alguns fundamentos de sua perspectiva em James (Maslow, 1968; Frankl, 1978; Rogers, 1974). Parece que tais vinculações se tornam facilmente reconhecidas quando nos referimos às funções adaptativas da emoção, da percepção, enfim, da consciência. No entanto, como relacionar os elementos presentes nas obras jamesianas com as filosofias fenomenológicas e existenciais, que tentam afastar-se do aspecto psicológico da consciência ou que até mesmo criticam a Psicologia em sua positividade ou negam o psiquismo com veemência? É justamente na busca desses elementos em comum entre $\mathrm{o}$ pensamento de James e o fenomenológico e existencial que nos deteremos a seguir. Iniciaremos, entretanto, apresentando as diferentes perspectivas do pensamento de James.

\section{As diferentes fases do pensamento de William James}

Como já dissemos, Tripicchio refere-se a dois momentos distintos nas obras de James: o dos escritos psicológicos e o dos 
filosóficos. Tripicchio (2007) identifica as obras psicológicas nos temas acerca das dicotomias: interno e externo, pensamento e afeto, conhecimento e emoção, ideias e sentimentos. A teoria das emoções jamesianas, com base nas teses darwinistas, revela a tentativa de James de transformar a Psicologia em uma ciência natural. James filósofo é aquele que sofre uma influência direta do pragmatismo de Peirce. James, pragmatista, em suas concepções sobre a verdade, nega a verdade representacional e defende a ideia de que a verdade se encontra intimamente relacionada às ações humanas. Para esse estudioso, o verdadeiro é o útil, que facilita a vida em seu cotidiano.

Na mesma linha de Tripicchio, sustentamos que a amplitude atingida pelos escritos de James nos permite identificar três vertentes presentes nas suas obras. Aliás, assim precisamos caminhar para poder, então, estabelecer os encontros e os desencontros entre os estudos de James e os da fenomenologia e da filosofia da existência. Ao estudar as obras de William James, identificamos três grandes ramificações do pensamento desse estudioso. Em um desses momentos, suas discussões em muito se aproximam de uma postura epistemológica, em que ele tenta encontrar uma posição solucionadora do interminável debate entre os racionalistas e os empiristas, com relação ao espaço onde podemos encontrar a verdade. Em outra ramificação, identificamos que sua preocupação se dirige à Psicologia de modo a estabelecer o seu status de ciência natural e totalmente autônoma. Por fim, James, em um texto de 1904, em que trata do empirismo em sua máxima radicalização, reaproxima-se da Filosofia, não mais com preocupações acerca do espaço onde se encontra a verdade, mas compartilhando das discussões, muito presentes em sua época, que questionam a existência da consciência.

\section{O pragmatismo de James}

Ao posicionarmos o pragmatismo como uma das modalidades do pensamento de James, utilizamo-nos das referências encontradas em Hessen (1926/1987). Esse estudioso denomina teoria do conhecimento ou epistemologia aquela área de estudo que trata do comportamento teórico, seja a teoria do conhecimento científico, seja a da ciência. A epistemologia interessa-se pelo questionamento acerca da verdade do conhecimento, expressa na concordância entre o pensamento e o objeto bem como na sua origem.

Hessen, em seus estudos sobre a teoria do conhecimento, mostra, de forma sintética, como a epistemologia aparece no cenário da Filosofia na Idade Moderna. Segundo ele, a discussão acerca do conhecimento surge com John Locke, que, em Ensaio sobre o Entendimento Humano, em 1690, trata das questões sobre a origem, a essência e a certeza do conhecimento humano. Leibnitz, em Novos Ensaios sobre o Entendimento Humano, em 1765, refuta as ideias de Locke. Outros filósofos da teoria do conhecimento foram George Berkeley, que publicou, em 1710, o Tratado dos Princípios do Conhecimento Humano, e David Hume, que, em 1748, publicou Investigação sobre o Entendimento Humano. Emmanuel Kant, em 1781, demarca seu lugar na epistemologia com A Crítica da Razão Pura, no qual tenta dar uma fundamentação crítica do conhecimento científico da natureza. Kant pretende buscar a validade lógica do conhecimento, questionando se é possível conhecer, sobre que bases se conhece e em que pressupostos se assenta o conhecimento (Hessen, 1926/1987).

Hessen dá prosseguimento a sua investigação acerca das diferentes posições das teorias do conhecimento, utilizando-se do método fenomenológico. Esse autor destaca que 
"A descrição fenomenológica pode e deve descobrir os problemas que se apresentam no fenômeno do conhecimento e fazer com que tomemos consciência deles" (Hessen, 1926/1987, p. 34). fenomenologia é método, e não teoria, e que a teoria do conhecimento tem como objetivo explicar e interpretar filosoficamente o problema do conhecimento; já a fenomenologia descreve o fenômeno do conhecimento. Com relação ao conhecimento, Hessen afirma que cabe à fenomenologia esclarecer a concepção natural do ato de conhecer, sem jamais decidir sobre a sua veracidade: "A descrição fenomenológica pode e deve descobrir os problemas que se apresentam no fenômeno do conhecimento e fazer com que tomemos consciência deles" (Hessen, 1926/1987, p. 34). Trata-se apenas de uma preparação que nos conduz ao problema.

Assim, Hessen nos diz que são cinco os problemas apontados pela descrição fenomenológica: o primeiro refere-se à possibilidade do conhecimento que implica sempre uma relação sujeito e objeto, em contato mútuo em que o sujeito apreende o objeto. Está em jogo aí a concepção de consciência natural, cabendo perguntar acerca da possibilidade do conhecimento: "Pode o sujeito apreender realmente o objeto?" (Hessen, 1926/1987, p. 35). Hessen coloca nesses posicionamentos as seguintes perspectivas: dogmatismo, cepticismo, subjetivismo e relativismo, pragmatismo e criticismo.

O segundo problema refere-se à origem do conhecimento. Está em jogo nessa modalidade a posição dualista, que, considerando a estrutura do sujeito cognoscente e o fato de o homem ser espiritual (razão) e sensível (experiência), pergunta pela origem do conhecimento humano. E as respostas aparecem nos seguintes segmentos: racionalismo, empirismo, intelectualismo e apriorismo.

O terceiro elemento encontrado fenomenologicamente diz respeito à essência e à determinação do conhecimento humano na relação sujeito e objeto, para o qual o problema central da teoria do conhecimento se encontra na relação sujeito e objeto, logo, é o sujeito que determina o objeto ou é o objeto que determina o sujeito? A quarta perspectiva encontrada refere-se às formas do conhecimento humano: racional e intuitiva. Por fim, a quinta modalidade epistemológica diz respeito ao critério da verdade, em que se pergunta qual é o critério que estabelece se o conhecimento é ou não verdadeiro.

Com base nessas considerações de Hessen é que consideramos James um teórico do conhecimento ao assumir um posicionamento denominado pragmatismo, que diz respeito à possibilidade de conhecer e ao critério de verdade. Em sua segunda conferência, intitulada $O$ que Significa o Pragmatismo, James (1912/1976) sugere que o método pragmático seria aquele que põe fim à disputa interminável entre os diferentes epistemólogos, e assim define o método pragmático como aquele que visa às consequências práticas.

Kinouchi (2007) refere-se a três modulações do pragmatismo. A primeira é a de Charles Sandero Peirce, o primeiro a utilizar-se dessa denominação. Ele considera o pragmático em seu caráter normativo, como um modelo intelectualista, que conduz à prática racional. Para William James, o pragmático é tomado em seu sentido utilitarista, totalmente associado ao praticalismo. John Dewey, principal figura do pragmatismo do século $X X$, entrelaça as duas modalidades de pragmatismo em uma perspectiva antropológica. Kinouchi conclui que nos três há uma tentativa de lidar com o problema da verdade, tal como o faz Hessen. Este afirma que o pragmatismo constitui uma teoria do conhecimento que se opõe ao ceticismo. Embora em ambas ocorra um afastamento da concepção de verdade como representação ou correspondência entre a realidade e o ser, o ceticismo nega toda e qualquer possibilidade do conhecimento e verdade, enquanto o pragmatismo argumenta 
que verdadeiro é aquilo que tem uma utilidade, e que o homem é eminentemente prático. Logo, no pragmatismo, a vontade, a ação e os motivos humanos são soberanos. A razão e o pensamento, como um valor derivado, são apenas elementos de orientação do homem frente à realidade. Hessen reconhece William James como o fundador do pragmatismo moderno, e aponta Schiller como seguidor dessa corrente epistemológica. James esclarece que a palavra pragmatismo foi encontrada por ele, pela primeira vez, em um artigo de Charles Peirce, de 1878, no qual este sustentava que as crenças são regras da ação. James, por sua vez, não se preocupa com as regras, e sim, com o caráter utilitarista a que se destinam as ações humanas. Kinouchi salienta que "o pragmatismo de James às vezes parece soar como uma espécie de existencialismo utilitarista" (2007, p. 220). Rossi afirma que James foi o protagonista da união do pragmatismo com o humanismo:

\begin{abstract}
James fue, ante todo, un humanista que encontró en el movimiento pragmatista un espacio propicio para exponer sus concepciones generales respecto de las múltiples relaciones entre el hombre y su entorno. Y si como pragmatista se reconoce que James supo vislumbrar y enfatizar la importancia de los conceptos de acción, creencia y voluntad; como humanista, es claro que supo cómo privilegiar las nociones de sentimiento, cambio e energía, entre otras (Rossi, 2008, p. 77)
\end{abstract}

Conclui Rossi que o pragmatismo de James se destaca por criticar a dicotomia cartesiana com ênfase no sujeito cognoscente, passando a valorizar a dimensão prática do conhecimento. James critica a Filosofia em seu caráter de contemplação, e adota uma posição que se aproxima de um empirismo, que coloca a Filosofia como uma atividade utilitária a serviço do homem.

\section{A Psicologia como ciência natural}

No final do século XIX, Wundt (1832-1920) e William James (1842-1910) inauguram a Psicologia em um viés de projeto científico, que receberá a denominação de Psicologia moderna, distinguindo-a de um projeto metafísico, em que a Psicologia consistia no estudo da alma. Para Abib (2009), a Psicologia moderna, como projeto de Psicologia científica, nasce de uma reflexão epistemológica com fins a uma epistemologia unitária. No entanto, ocorre com Wundt e James o mesmo que acontece em toda a história da Psicologia: seus iniciadores partem de concepções diferentes, decorrendo daí variadas e multifacetadas psicologias. Abib chama a atenção para a elaboração da ciência psicológica como conhecimento plural; resulta daí que a Psicologia acaba por constituir-se em meio a uma epistemologia pluralizada.

O movimento pragmatista de James vai receber, na Psicologia moderna, a denominação de funcionalismo, em oposição ao estruturalismo de Wundt. Tilquin marca bem essa distinção ao afirmar que “... o estruturalismo é como a anatomia do espírito, enquanto o funcionalismo é como a fisiologia" (1950 como citado em Tourinho, 2009, p. 31). Abib (2009) ressalta que a psicologia de Wundt se constitui como uma ciência empírica, e que a psicologia de James se aproxima de uma ciência natural. Wundt pretende fazer uma ciência psicológica, buscando as leis da causalidade presentes no psiquismo. O esforço de James, na tentativa de tornar a Psicologia uma ciência natural, consiste em estudar os fatos mentais em relação com o ambiente físico. Nas definições dos conceitos de pensamento, hábito, atenção, emoção e consciência com os quais James vai trabalhar, a preocupação incidia sobre as funções do organismo, e não sobre as suas propriedades. É na perspectiva de função é que ele trata dos diferentes temas 
da Psicologia. Com relação ao pensamento, James afirmava que esse era fluxo contínuo, e as referências de tempo e espaço eram constituídas em função das ações para as quais o pensamento se destinava. Sobre os hábitos, ele dizia que eram aprendidos pela força adaptativa do organismo. Ao estudar as emoções, inverte a tese que sustentava que um estímulo emotivo suscitava toda uma reação orgânica. Esse psicólogo funcionalista explica que ocorre o contrário: primeiro há a reação do organismo, e é esta que desencadeia a emoção (Ferreira \& Gutman, 2008).

Em 1890, James escreve seu livro clássico acerca da Psicologia, intitulado Principles of Psychology, adotando uma perspectiva totalmente funcionalista com a seguinte tese: "os mecanismos psicológicos existem porque são úteis e auxiliam os indivíduos a sobreviver e a realizar atividades importantes para a adaptação às exigências do meio" (James, 1890 como citado em Tourinho, 2009 , p. 30). Nesse sentido, o funcionalismo encontra-se presente, uma vez que o psiquismo humano se constitui por um mecanismo que visa sempre a consequências práticas; logo, a determinação psíquica se dá teleologicamente. Importa, então, ao investigador do fenômeno psíquico, as operações das atividades mentais ao buscar as metas futuras e a escolha dos meios para alcançá-las em circunstâncias reais. O pensar, o sentir e os motivos vão paulatinamente modelando-se para atender às exigências utilitárias advindas do mundo, até se adaptarem ao meio e se tornarem autônomos. Com o conhecimento, por parte dos psicólogos modernos, dessas funções do psiquismo, poderiam eles prever e controlar as ações humanas e, assim, ensinar aos homens como deveriam agir de modo a resolver seus problemas. Esse caráter naturalista do funcionalismo parece aproximar-se em muito da perspectiva empírica, que, na Psicologia, é radicalmente assumida pelo behaviorismo. Mas o que diz James acerca disso?
James (1912/1976) afirma que, embora o pragmatismo se aproxime da proposta empirista, ambas apresentam uma acentuada diferença. O pragmatismo encontra-se totalmente apartado da preocupação empirista de estabelecer abstrações e princípios, alcançando, assim, o elemento mais original e a verdade absoluta. A perspectiva pragmática é apenas um método, uma orientação que pretende alcançar o valor do prático na experiência com a qual se encontram os caminhos passíveis para modificação das realidades. Trata-se muito mais de instrumentos do que de teorias. Os instrumentos são ferramentas, meios para atingir fins determinados.

O pragmatismo consiste, em um sentido amplo, em uma teoria da verdade na medida em que desenvolve procedimentos que visam a conduzir as experiências de modo satisfatório, simplificando e economizando trabalho. Trata-se da verdade como instrumental, e não como teoria. É nesse aspecto que, no pragmatismo jamesiano, encontramos as bases para o que, em Psicologia, se denominou funcionalismo. Nessa ênfase, destacam-se alguns escritos de James, como Principles of Psychology (1890/1952), um verdadeiro tratado de Psicologia com cerca de 800 páginas.

Com o funcionalismo dos Principles of Psychology, temos o que consideramos o segundo momento do pensamento jamesiano, em que James pretende que a Psicologia se torne uma ciência natural, conquistando total independência da metafísica. A Psicologia, como ciência da natureza, aproximar-seia muito mais da Biologia. Assim, ele tece consideráveis críticas à concepção de eu com sentidos e determinações dados em si mesmo e, portanto, substancializado, tal como foram tomados pelas filosofias da subjetividade, desde Descartes, passando por Kant até Hegel. Por outro lado, também rejeita a ideia que defende a inexistência do 
James ( 1890 como citado em Abib, 2009, p. 203) diz ainda que "a consciência é um órgão, uma perfeição superadicionada pela evolução, com a função de adaptar as pessoas aos ambientes, com a função, portanto, de ajudá-las a sobreviver". Logo, nessa perspectiva, à Psicologia funcionalista, caberia o estudo das funções cerebrais e dos fenômenos cognitivos, volitivos e perceptivos, para oferecer resultados práticos por meio de suas ações terapêuticas. eu, ficando esse, então, reduzido a um feixe de sensações. Segundo Abib: "Tem-se então que Wundt e James lançam os fundamentos da Psicologia moderna com base em uma teoria do sujeito concebido como devir, e não como ser" (2009, p. 203). James (1890 como citado em Abib, 2009, p. 203) diz ainda que "a consciência é um órgão, uma perfeição superadicionada pela evolução, com a função de adaptar as pessoas aos ambientes, com a função, portanto, de ajudálas a sobreviver". Logo, nessa perspectiva, à Psicologia funcionalista, caberia o estudo das funções cerebrais e dos fenômenos cognitivos, volitivos e perceptivos, para oferecer resultados práticos por meio de suas ações terapêuticas.

Ainda em Principles of Psychology, James propõe-se a estudar a mente a partir dela mesma, e não como vinha acontecendo na Psicologia, que a estudava a partir das sensações. Para James, o pensamento significa toda a forma de consciência, e o autor lista cinco características que apontam o modo como o pensamento acontece em uma consciência pessoal: é sempre parte da consciência, está em constante mudança, é sensivelmente contínua, lida sempre com objetos independentes, focase em partes dos objetos e exclui outras partes. No entanto, a ideia de consciência como algo que se encontra em um dos polos vai paulatinamente desaparecendo no funcionalismo de James. Segundo Heidbreder (1933/1981), James, após a publicação dos princípios em Psicologia, foi desinteressandose pela Psicologia e acreditando que as respostas para as suas indagações só pudessem ser encontradas na Filosofia, até que, em 1904, ele escreve o primeiro capítulo em seu livro Essays in Radical Empiricism, que tem o seguinte título: Does Consciousness Exist?

\section{A filosofia empírica em James}

Temos, então, o que denominamos de terceiro momento jamesiano, em que ele se reaproxima da Filosofia; agora encontrandose em uma posição que ele mesmo considera empírica, chega a afirmar que concebe a consciência como função de conhecer da própria experiência, e nada mais. Heidbreder (1933/1981, p. 139) observa que "a psicologia de James é a transição: mostra os sinais da metafísica, porém é um movimento orientado para a ciência". Apostaríamos então dizer que, em James, encontramos outra radical e imprescindível transição, que é de uma Psicologia como ciência natural, que se dedica ao estudo do estado da consciência, de seus fenômenos e seus fundamentos biológicos (condições) a uma Psicologia que prescinde de um psiquismo. Assim, ao questionar a existência da consciência, ele refere-se, em seu texto A Consciência Existe? (James, 1904), a diferentes estudiosos que já tinham abandonado tal noção, e apresenta os argumentos a favor de sua inexistência.

Em 1904, James decide, então, defender publicamente a ideia de que a consciência deveria ser descartada, restando apenas a sua função, que é a de conhecer. Ele substitui a noção de consciência pelo seu equivalente pragmático: realidades da experiência, que sempre se dão em uma exterioridade, e, com isso, tenta romper a dicotomia consciência e mundo, afirmando que, ao considerar a experiência absoluta, acaba por prescindir totalmente de dita polaridade. James acrescenta que a relação desses dois termos é a própria experiência, e que um dos seus termos é o "sujeito que conhece", e que o outro é o "objeto conhecido"; "Ela tem dois papéis diferentes, sendo gedanke e gedachtes, o pensamento-de-um-objeto e o objetopensado, ambos em um" (James, 1904, p.108).

\section{Os legados de James à fenomenologia e à filosofia da existência}

Ao retomarmos as três modalidades presentes nos estudos de James (a epistemológica, a 
psicológica e a filosófica), poderemos então estabelecer os encontros e os desencontros no que diz respeito à posição epistemológica, à elaboração acerca da consciência e à valorização da experiência em detrimento do aspecto lógico do pensamento. Iniciaremos por buscar as aproximações entre James e Husserl por dois motivos. Sendo ambos contemporâneos, provavelmente encontravam-se imersos no mesmo âmbito de discussão das problemáticas acerca do conhecimento; em segundo lugar, em ambos existe uma preocupação em demarcar o espaço onde a consciência aparece.

Epistemologia refere-se a um segmento da Filosofia moderna que mantém um diálogo afinado com o projeto científico. Como Filosofia do conhecimento, pretende discutir a origem do conhecimento, o lugar da verdade e o seu acesso (método). Para tanto, a epistemologia precisa manter a dicotomia sujeito e objeto e assim estabelecer em qual deles se encontra a verdade, essência de tudo que há. Para alcançar a verdade, é preciso saber como acessá-la. Essa questão gerou intermináveis discussões entre os empiristas e os idealistas. Os primeiros diziam que a verdade se encontrava no real, empírico, e que daí nós poderíamos estabelecer todas as leis de tudo o que há. O acesso a essa verdade e às suas leis dar-se-ia pela experimentação, comprovação e corroboração das hipóteses. Já os segundos afirmavam que a verdade se encontrava na razão, no pensamento, e que, pelas leis do pensar e suas faculdades, poderíamos acessar toda a verdade sobre as coisas. Acessá-la seria um exercício do pensamento.

Tanto James quanto a fenomenologia husserliana e a filosofia da existência de Kierkegaard, Heidegger e Sartre opõemse às teorias do conhecimento, embora por caminhos diferentes. James propõe que abandonemos essas discussões de ordem teórica e busquemos a verdade na vida prática, na ação. Nisso consiste sua perspectiva pragmática. Para Hessen (1926/1987), essa tese jamesiana ainda é epistemológica, pois guarda na sua essência uma dicotomia com relação ao fato de que a ação ainda deriva da vontade do homem. A vontade ainda é uma faculdade, e, como tal, encontra-se no polo da subjetividade. Husserl (1901/2007a), com sua fenomenologia, também pretende deslocar-se das discussões epistemológicas, que precisam partir da dicotomia homem e mundo, para então posicionar a verdade. Husserl propõe a ideia de que o acesso à verdade não é alcançado desprezando ou minimizando a importância de um dos polos, pois a verdade encontrase no espaço cooriginário ao sujeito e ao objeto: a intencionalidade. Por isso, afirma que todo o objeto é para a consciência como a consciência é para o objeto. Sem dúvida, Husserl mantém-se em uma filosofia que pressupõe a subjetividade, mesmo que não Ihe confira o lugar de posicionadora. Vemos, assim, que a discussão acerca da verdade, tanto com relação à tentativa de afastar-se das vertentes epistemológicas como no que diz respeito à relação que ainda mantém com essa vertente filosófica, parece ser um ponto de encontro entre esses dois pensadores.

Holanda defende a aproximação da noção de consciência entre James e Husserl da seguinte forma: "mesmo negando o caráter substancial da consciência, James - ao afirmála como função - finda por posicioná-la como um ente, como uma realidade, na acepção fenomenológica, sendo, portanto, um objeto suscetível de investigação" (2012). Campos (1945 como citado em Holanda, 2012) também argumenta a favor dessa proximidade, ao dizer que James, ao opor-se ao atomismo, adota uma "atitude fenomenológica, o que o torna precursor das ideias de Husserl" (Campos, 1945, p. 37, como citado em Holanda, 2012). Concluindo, atentemos ao que nos lembra Holanda: "Ademais, o próprio Husserl afirmara a importância do valor do 
Principles of Psychology para o campo da Psicologia descritiva"(2012). Mas, e o ponto de discórdia, qual seria?

Husserl (1910/2007b) é um crítico fervoroso das psicologias que se estabeleceram até o início do século $X X$, e ponderava, em A Filosofia como Ciência Rigorosa, que a Psicologia clássica se preocupava com os estudos sobre a alma, suas disposições e seus afetos. Partindo desse a priori, postulava que a Psicologia havia acabado por desconsiderar totalmente a natureza intencional dos fenômenos psíquicos. Já a Psicologia moderna, mesmo que com um projeto de ciência natural, havia desconsiderado completamente a natureza dos fenômenos psíquicos em suas investigações e formulações, apenas substituindo a denominação alma por conceitos tais como subjetividade, atividade subjetiva, eu, self e personalidade, dentre outros. Mantendo-se no naturalismo, ela toma o psiquismo como fenômeno natural, e, como tal, busca encontrar sempre um por que de seu acontecer (Feijoo, 2011). Essa consideração de Husserl revela uma crítica ao projeto de Psicologia presente em James. Vamos agora buscar o que compõe a noção de consciência em James e assim tentar apontar os elementos de consciência comuns nesses dois pensadores.

Para James, a consciência é ação, fluxo e pensamento. Para Husserl, a consciência é intencionalidade; logo, também é fluxo temporal, sínteses de vivências intencionais. Husserl afirma veementemente que a intencionalidade deveria ser considerada o fenômeno psíquico por excelência. Por intencionalidade, Husserl entende o fato de toda consciência já ser sempre consciência de..., assim, os fenômenos psíquicos são estruturados de modo não posicionadores. Nossa consciência já está sempre aberta, e é esse caráter de abertura que a marca. Em consequência, uma psicologia que se pretenda fenomenológica deve considerar a intencionalidade um fenômeno psíquico, e, como tal, afastar-se de qualquer perspectiva causal, mesmo que teleológica. Assim, Husserl não compartilha os pressupostos funcionalistas, cuja ação sempre está destinada a um fim posicionado pela consciência.

Em uma Psicologia clínica com bases funcionalistas, o que está em questão é de que modo podemos alcançar a ação correta para atingir os fins que conduzam ao bem viver. Nas clínicas fenomenológicas, a pretensão é desfazer as aglomerações, que estão presentes na síntese do fluxo incessante que constitui a consciência, para que, dessa forma, as recordações, as expectativas e as percepções não formem um bloco de aglomerados, de modo que aquilo que é questão acabe por desaparecer.

A disciplina Psicologia: Fundamentos e Bases do Pensamento Fenomenológico e Existencial em sua denominação e em sua ementa aponta ainda, em James, a base das psicologias da existência. Para pensarmos acerca dessas psicologias, primeiramente, cabe trazer à discussão as filosofias que as fundamentam. As filosofias da existência caracterizam-se por resgatar aquilo que nas filosofias da subjetividade havia sido abandonado, ou seja, o caráter sensível da existência, sem recair na empiria, que posiciona o sensível como mera experiência. Assim, também essas filosofias pretendem ser críticas tanto com relação ao empirismo quanto ao idealismo; assumem a posição da existência como espaço do acontecimento, saindo assim da ideia de subjetividade tal como foi incorporado pelas psicologias do eu. Como se sabe, o conceito heideggeriano de existência, ao contrário do que pode parecer, nada tem a ver com o ato de ser, de estar fativelmente presente. A existência, como existir, significa ek-sistir, ser-arremessado-para-fora-de-si, jogado em direção ao horizonte histórico-mundano de 
realização de si. A clínica existencial consiste em um espaço compartilhado no qual se pretende proporcionar possivelmente, e não necessariamente, transformações existenciais. O clínico não intervém; acompanha. Ele não provoca; participa; enfim, compartilha do espaço que se abre para uma possível transformação.

Ao buscar as aproximações de James com a perspectiva existencial em Psicologia, deparamo-nos com o texto de James (1904) que questiona se realmente a consciência existe. Nesses questionamentos, embora James assuma uma posição empírica, encontramos uma aproximação com a máxima das filosofias existenciais que defendem a indeterminação e o caráter de negatividade da existência. Ambos, ao extinguir a consciência, pretendem eliminar definitivamente todas as formas de dualismo.

\section{Considerações finais}

Podemos pensar, em um primeiro momento, que, com as considerações de James acerca da consciência, do método e de prática psicológica em seus diferentes posicionamentos, encontraríamos a gênese das fundamentações da fenomenologia e das filosofias da existência; porém, em uma análise mais detalhada, concluímos que há muito mais aspectos divergentes do que convergências entre James, em seus três momentos aqui postulados, a fenomenologia de Husserl e a filosofia existencial.

James, em seu posicionamento acerca da consciência, apresenta um deslocamento tanto do idealismo quanto do empirismo, do mesmo modo que Husserl, pela fenomenologia, pretende suspender as hipostasias idealistas e realistas. Mesmo a consciência em James sendo fluida, ele ainda mantém a ideia de que é a ação do homem que posiciona o mundo. Em Husserl, a consciência é uma síntese incessante também em fluxo vivencial; no entanto, mundo e homem são cooriginários.

Com relação ao método empregado em suas análises, afirmam Bertoni e Pinto (2007) que James pretende imprimir à sua investigação um tratamento empírico com ênfase na experiência concreta, por entender como fenômeno psicológico aquilo que pode ser descrito sem nenhuma especulação metafísica. No projeto fenomenológico de Husserl, a atitude fenomenológica frente ao fenômeno consiste em uma atitude antinatural com a qual Husserl nos convida a irmos ao fenômeno tal como ele se mostra à consciência, portanto, não empiricamente. $\mathrm{E}$ ainda ressaltamos a questão da intencionalidade como espaço de realização das vivências, que a noção de experiência em James não contempla. Em James, o funcionalismo diz respeito ao pressuposto de que a experiência serve a uma função que é adaptativa, logo, tem bases em uma causalidade teleológica. Husserl, ao considerar a cooriginalidade consciência e objeto, suprime qualquer intervalo espaçotemporal e, em consequência, a relação de causalidade.

Mesmo a conclusão de James acerca da inexistência da consciência é insuficiente para abarcar o caráter de negatividade do existir demarcado pelas filosofias da existência e do qual emergem a angústia, o desespero e o tédio como marcas dessa própria negatividade e anúncio da abertura às possibilidades.

Ainda com relação à clínica psicológica que em James conduziria ao bem-estar, à adaptação e à superação -, na perspectiva existencial, a clínica não levaria a nenhuma positividade, ao contrário, abre espaço, ou, pelo menos, não impede tal abertura, para que o negativo se anuncie como tal para que transformações possíveis se apresentem como tais. 


\section{Ana Maria Lopez Calvo de Feijoo}

Doutora em Psicoterapias Atuais pela Universidade Federal do Rio de Janeiro e docente da Universidade do Estado do Rio de Janeiro, Rio de Janeiro - RJ - Brasil.

E-mail: ana.maria.feijoo@gmail.com

\section{Endereço para envio de correspondência:}

Universidade do Estado do Rio de Janeiro, Departamento de Psicologia Clínica, Instituto de Psicologia. Rua São Francisco Xavier, 524, Maracanã. CEP: 20550-013. Rio de Janeiro, RJ.

Recebido 30/08/2012, Aprovado 11/04/2013.

\section{Referências}

Abib, J. A. D. (2009). Epistemologia pluralizada e história da psicologia. Scientiae Studia, 7(2), 195-208. doi: http://dx.doi. org/10.1590/S1678-31662009000200002

Bertoni, P. G., \& Pinto, D. C. (2007). Mudança e continuidade: a formulação jamesiana de pensamento como fluxo. Psicologia: Reflexão e Crítica, 20(2), 205-211. doi: http://dx.doi. org/10.1590/S0102-79722007000200005

Boris, G. (2011). A (pouco conhecida) contribuição de Brentano para as psicoterapias humanistas. Revista da Abordagem Cestáltica, XVII(2), 199-203.

Feijoo, A. M. (2011). A existência para além do sujeito: a crise da subjetividade moderna e suas repercussões para a possibilidade de uma clínica psicológica com fundamentos fenomenológico-existenciais. Rio de Janeiro: Viaverita Editora.

Ferreira, A., \& G. Gutman (2008). O funcionalismo em seus primórdios: a psicologia a serviço da adaptação. In A. M. Jacó Vilela, \& F. Portugal, (Orgs.), História da psicologia: rumos e percursos (pp. 121-139). Rio de Janeiro: Nau Editora.

Ferreira, A., \& Arruda, A. (2010). O funcionalismo: a psicologia nos trilhos da adaptação. In A. Arruda \& L. Ferreira (Orgs.), A pluralidade do campo psicológico (pp. 71-89). Rio de Janeiro: Editora da UFRJ.

Frankl, V. (1978). Fundamentos antropológicos da psicoterapia. Rio de Janeiro: Zahar Editores.

Gutman, G. (2008). As novidades da psicopatologia estão no século XIX? O retorno a William James e à sua "teoria das emoções". Revista Latinoamericana de Psicopatologia Fundamental, 11(4), 661-668. doi: http://dx.doi.org/10.1590/ S1415-47142008000400012

Hessen, J. (1987). Teoria do conhecimento (António Correia, trad.). Coimbra: Arménio Amado (Trabalho original publicado em 1926).

Heidbreder (1981). Psicologias do século XX. (Lauro S. Brandy, trad.). São Paulo: Mestre Jou (Trabalho original publicado em 1933).

Holanda. A. (2012). O método fenomenológico em psicologia.
Uma leitura de Nilton

Campos. Estudos e Pesquisas em psicologia, Rio de Janeiro, 12(3), 817-832.

Husserl, E. (2007a). Investigações lógicas (Vols. 1-2, P. Alves \& C. Marujão, trads.). Lisboa: Centro de Filosofia da Universidade de Lisboa (Trabalho original publicado em 1901).

Husserl, E. (2007b). La filosofía como ciencia estricta (E. Taberning, trad.). La Plata: Terramar Ediciones. (Trabalho original publicado em 1910).

James, W. (1904). Does consciousness exist? Journal of Philosophy, Psychology, and Scientific Methods, 1, 477-491.

James,W. (1952). The principles of psychology. In Britannica Great Books of the Western World. Chicago: Chicago University Press (Trabalho original publicado em 1890).

James W. (1976). Essays in radical empiricism. Cambridge: Harvard University Press (Trabalho original publicado em 1912).

Kinouchi, R. (2007). Tão perto, tão distante: William James e a psicologia contemporânea. Scentie Studia, 5(2), 215-226. doi: http://dx.doi.org/10.1590/S1678-31662009000200009

Maslow, A. H. (1968). Introdução à psicologia do ser (Álvaro Cabral, trad.). Rio de Janeiro: Eldorado.

Rogers, C. (1974). Psicoterapia e consulta psicológica. Lisboa: Moraes Editores.

Rossi, P. (2008). Tensiones dialecticas en el pragmatism humanista de William James. Límite, Revista de Filosofía y Psicología 18(3), 71-89.

Tourinho, C.D. (2009). Fundamentos epistemológicos da psicologia. In C. Tourinho, \& R. Sampaio, (Orgs), Estudos em psicologia: uma introdução (pp. 17-36). Rio de Janeiro: Proclama Editora

Tripicchio, A. (2007). William James: filósofo, psicólogo e médico. Recuperado em 06 jan., 2012, de http://www.redepsi.com. br/portal 